\title{
REMOVAL OF REACTIVE RED 198 FROM AQUEOUS SOLUTIONS USING MODIFIED CLAY: OPTIMIZATION, KINETIC AND ISOTHERM
}

\author{
PARISA ASHNA ${ }^{a}$ AND ROUHOLLAH HEYDARI ${ }^{b, *}$ \\ ${ }^{a}$ Department of Environmental Engineering, West Tehran Branch, Islamic Azad University, Tehran, Iran. \\ ${ }^{b}$ Research Center for Environmental Determinants of Health, Kermanshah University of Medical Sciences, Kermanshah, Iran.
}

\begin{abstract}
Dyes are large group of environmental pollutions with complex molecular structure and resistant to biodegradation. The entrance of these compounds into the water sources causes health problems in humans and many aquatic organisms. Therefore, colored effluents have to be adequately treated before discharging into the environment. This study aimed to evaluated efficiency of adsorption process of modified clay by cetyltrimethylammonium bromide (CTAB) in removal of Reactive Red 198 (RR 198) from aqueous solution. The modified clay was prepared and its characterization was accomplished by Fourier transform infrared (FT-IR) spectroscopy, X-ray diffraction (XRD) and scanning electron microscopy (SEM). The influences of major operational parameters on the efficiency of adsorption process were investigated and optimized. Kinetic and isotherm of adsorption were determined. The results revealed that increasing $\mathrm{pH}$, initial concentration, ionic strength and temperature decrease rate of dye removal and increasing adsorbent dosage increases the dye removal efficiency. The maximum removal efficiency (99.61\%) of RR 198 with modified clay was at pH; 3, time; $60 \mathrm{~min}$, adsorbent dosage; $0.1 \mathrm{~g} / \mathrm{L}$ and initial concentration; $20 \mathrm{mg} / \mathrm{L}$. The experimental data fitted well to the Langmuir isotherm model and exhibited a maximum adsorption capacity $\left(\mathrm{q}_{\max }\right)$ of $25.84 \mathrm{mg} / \mathrm{g}$, which followed the pseudo-second-order equation. The adsorption process shows an intra-particle diffusion mechanism. According to the results, modified montmorillonite clay can be considered as an effective and promising adsorbent for the removal of RR 198 from aqueous solutions.
\end{abstract}

Keywords: Reactive Red 198; modified clay; cetyltrimethylammonium bromide; adsorption isotherm; reaction kinetic.

\section{INTRODUCTION}

Dyes are organic compounds that widely used in the textile, paper, plastic, and leather industries to color commercial products. The organic dyes in industrial wastewater pose serious environmental problems due to their toxicity and poor biodegradability and lead to risk human health [1]. The presence of dyes not only hampers the aesthetic quality of water but also affects and alters the aquatic ecosystem by prevents sunlight and oxygen penetration, which can significantly reduce photosynthetic activities in aquatic systems [2]. About 10,000 different commercial dyes and pigments are being manufactured which means over $7 \times 108$ kilograms production in world annually. It has been estimated that about $10-20 \%$ of these dyes are released to effluents during the dyeing processes [3].

In general, dyes used in textile industries can divided into several groups, including anionic dyes (acidic, direct, and reactive), cationic dyes (alkaline dyes), and non-anionic dyes (disperse dyes). Reactive dyes have high solubility in water and used in many dying processes, especially for dying wool and polyamide fiber. Also their variety, easy applicability, desired stability of the finished product, and low energy consumption impose their widely usage in the textile industry [4]. Reactive Red 198 (RR 198) dye is mostly utilized in textile industry. Due to high water solubility of RR 198 and hydrolysis in alkaline conditions, large portions of this reactive dye is wasted during dyeing processes and discharged in wastewater $[5,6]$.

Various physical, chemical, biological and physico-chemical processes have been reported to removal the dyes and drugs from wastewaters [7-15]. Unfortunately, dyes are toxic, non-biodegradable, recalcitrant organic molecules, and even stable to oxidizing solutions. Thus, to overcome the challenge of colored effluents, adsorption process is proven as a reliable and effective process. Simplicity in process design, ease in operational conditions and economical aspects are some of the major advantages of adsorption process [2].

Activated carbon (AC) as a global and traditional adsorbent widely is used for remove of organic and inorganic pollutions from wastewater [16, 17]. Due to well-developed pore structure and high internal surface area, AC has great ability in adsorption of dissolved organic compounds from industrial effluents. However, high operating cost of AC adsorption process, regeneration problems and difficulty in separation from the wastewater after use are disadvantageous of this adsorbent. Therefore, many efforts have been made to find low cost and applicable adsorbents [18]. Recently, clay materials are being considered as AC alternative due to having some advantages such as low cost, abundance in environmental and regenerability. Montmorillonite (MMT) is a kind of mineral clay that has been used in the removal of organic pigments and dyes because high surface area and cation exchange capacity. Nonetheless, surface of MMT has negative charges resulting in lowering surface interaction and adsorption for the same ions [19-21]. Therefore, in order to enhance MMT adsorption capacities for anionic dyes, the surface could be modified by some appropriate methods. The known modifiers usually are quaternary ammonium salts with long chain or other cationic surfactants. The characteristics of modified clays (organo clays) can be determined by surfactant properties, such as alkyl chain length and number of branches. The organophilic surface of organo clays aids in improving organic compounds adsorption [19]. In recent 20 years, it has been proved that the organo clays have higher adsorption capacity than the natural clay. Although modification of clays with surfactants increases their cost significantly, the resultant increase in adsorption capacity may still make surfactant-modified clays cost effective. So clay derivatives may be promising adsorbents for environmental and purification purposes.

This study aimed to investigate removal of RR 198 using modified clay by cetyltrimethylammonium bromide (CTAB) through considering key operating parameters such as solution $\mathrm{pH}$, initial dye concentration, adsorbent dosage, contact time, ionic strength and temperature. The experimental data were evaluated by Langmuir and Freundlich adsorption isotherms. The pseudo-first order and pseudo-second order kinetic models were studied to understand the kinetic of adsorption. The mechanism of adsorption was analyzed by intraparticle diffusion model.

\section{MATERIALS AND METHODS}

\section{Materials}

The used clay (montmorillonite) was purchased from Laviosa Co. (China). Cetyltrimethylammonium bromide (CTAB) and other chemical material were provided from Merck Co. (Darmstadt, Germany). Reactive Red 198 dye $\left(\mathrm{C}_{27} \mathrm{H}_{18} \mathrm{ClN}_{7} \mathrm{Na}_{4} \mathrm{O}_{15} \mathrm{~S}_{5}, \mathrm{MW}: 968.21 \mathrm{~g} / \mathrm{mole}\right)$ was obtained from ALVAN SABET Dyestuffs and Chemical manufacturer (Tehran, Iran).

\section{Preparation of cetyltrimethylammonium bromide - montmorillonite (CTAB-MMT)}

The synthesis of surfactant-modified MMT was conducted by the following procedure. $2.74 \mathrm{~g}$ of CTAB was dissolved in $200 \mathrm{~mL}$ distilled water. Then $10 \mathrm{~g}$ of MMT was added to the CTAB solution at $25^{\circ} \mathrm{C}$. The obtained solution was stirred for $24 \mathrm{~h}$ at $25^{\circ} \mathrm{C}$. The treated clay was separated from aqueous phase by vacuum filtration and washed several times by distilled water until that $\mathrm{Br}^{-}$in filtrate solution was not detected. The separated organo-clay was dried at 80-90 ${ }^{\circ} \mathrm{C}$, activated for $1 \mathrm{~h}$ at $105{ }^{\circ} \mathrm{C}$ and then mechanically grinded to less than 100 mesh. 


\section{Characterization of CTAB-MMT}

The crystalline structure of CTAB-MMT was characterized by X-ray diffraction (Shimadzu XRD-6000, Japan), and FT-IR spectra were obtained using a Bruker FT-IR spectrometer (model TENSOR 27, Germany). The morphological features and surface characteristics of CTAB-MMT were obtained from scanning electron microscopy (SEM) using a Hitachi scanning electron microscope (model S-4160).

\section{Batch adsorption experiments}

The amount of adsorbed RR 198 was measured as a function of time (10-150 min), solution $\mathrm{pH}$ (1-11), dye concentration (20-180 mg/L), adsorbent dosage $(1-0.1 \mathrm{~g} / \mathrm{L})$, ionic strength $(20-100 \mathrm{mg} / \mathrm{L})$ and reaction temperature $\left(15-45^{\circ} \mathrm{C}\right)$, by batch technique. The $\mathrm{pH}$ of the solutions was adjusted using $0.1 \mathrm{M}$ phosphate buffer. The prepared samples were agitated at $140 \mathrm{rpm}$ in thermostated shaker. Afterwards for any experiment, the solution was centrifuged at $4000 \times \mathrm{g}$ for $5 \mathrm{~min}$ and the concentration of RR 198 in supernatant was determined. The dye concentration was measured at a wavelength corresponding to the maximum absorbance $\left(\lambda_{\max }\right) 518 \mathrm{~nm}$, by a UV-VIS spectrophotometer (Jenway, model 6505 , UK). The removal efficiency $(\mathrm{R})$ and capacity $\left(\mathrm{q}_{\mathrm{e}}\right)$ were calculated by equations 1 and 2, respectively:

$\mathrm{R}(\%)=\frac{\left(\mathrm{C}_{0-} \mathrm{C}_{\mathrm{e}}\right)}{\mathrm{C}_{0}}$

$q_{e}=\frac{\left(C_{0}-C_{e}\right) V}{m}$

Where $q_{e}$ is the amount of adsorbed dye (mg/g) at equilibrium, $C_{0}$ and $C_{e}$ are the initial and equilibrium concentrations of dye in solution phase, respectively $(\mathrm{mg} / \mathrm{L})$.

\section{Adsorption kinetics and isotherm models}

\section{Adsorption kinetics}

Kinetic experiments were carried out in an Erlenmeyer containing $100 \mathrm{~mL}$ of RR 198 solution with initial concentration of $100 \mathrm{mg} / \mathrm{L}$. Experiment conditions were set according to the obtained optimum value for each parameter. After regular time intervals, $5 \mathrm{~mL}$ of solution was sampled from the mixture and dye concentration determined until the reaction reached to equilibrium. Two of the most widely used kinetic models namely pseudo-first-order and pseudo-secondorder model were used to find the adsorption kinetic behavior of RR 198 onto the CTAB-MMT.

The pseudo-first-order kinetic model is given as Eq. 3:

$\ln \left(q_{e}-q_{t}\right)=\ln q_{e}-k_{1} t$

Where $\mathrm{q}_{\mathrm{e}}$ and $\mathrm{q}_{\mathrm{t}}(\mathrm{mg} / \mathrm{g})$ are the amounts of RR 198 adsorbed at equilibrium and at any time $(\mathrm{min})$, respectively. The constant $\mathrm{k}_{1}(1 / \mathrm{min})$ is the adsorption rate constant of pseudo-first-order reaction, which determined from the slope of plot of $\ln \left(\mathrm{q}_{\mathrm{e}}-\mathrm{q}_{\mathrm{t}}\right)$ against $\mathrm{t}$.

The pseudo-second-order kinetic model is given as Eq. 4:

$\frac{t}{q_{t}}=\frac{1}{k_{2} q_{e}^{2}}+\frac{t}{q_{e}}$

Where $\mathrm{q}_{\mathrm{e}}$ and $\mathrm{q}_{\mathrm{t}}$ are defined above and $\mathrm{K}_{2}(\mathrm{~g} / \mathrm{mgmin})$ is the adsorption rate constant of pseudo-second-order adsorption.

\section{The intra-particle diffusion model}

To identify the mechanism which RR 198 diffuses to the CTAB-MMT surface (this information will be particularly useful for design purposes), the kinetic results were analyzed using the Weber and Morris intra-particle diffusion model [2]. Intra-particular diffusion was characterized using the relationship between specific sorption $\left(\mathrm{q}_{\mathrm{t}}\right)$ and the square root of time $\left(\mathrm{t}^{1 / 2}\right)$ by Eq.5:

$q_{t}=k_{i d} t^{1 / 2}+C$
Where $\mathrm{k}_{\mathrm{id}}$ is the intra-particle rate constant $\left(\mathrm{mg} / \mathrm{gmin}^{1 / 2}\right)$ and $C$ is the intercept. The intra-particle diffusion model implies that the plot of $\mathrm{q}_{\mathrm{t}}$ versus $\mathrm{t}^{1 / 2}$ should be linear.

\section{Langmuir and Freundlich isotherm}

Adsorption isotherms were investigated using a series of initial concentrations of RR 198. The amounts of adsorbent in all samples were constant. Langmuir and Freundlich isotherms are the common isotherms used in equilibrium studies. The equations of Langmuir and Freundlich isotherms (Eqs. 6 and 7) are expressed as follows:

$\frac{C_{e}}{q_{e}}=\frac{C_{e}}{q_{\max }}+\frac{1}{q_{\max } K_{l}}$

$\log q_{e}=\log k_{f}+\frac{1}{n} \log C_{e}$

Where $\mathrm{q}_{\max }$ is the maximum RR 198 adsorbed $\left(\mathrm{mg} / \mathrm{g}\right.$ ) and $\mathrm{K}_{\mathrm{l}}$ is the Langmuir constant related to the affinity of binding sites $(\mathrm{L} / \mathrm{mg}) . \mathrm{K}_{1}$ and $\mathrm{q}_{\max }$ calculate from the plot of $\mathrm{Ce} / \mathrm{q}_{\mathrm{e}}$ against $\mathrm{C}_{\mathrm{e}} . \mathrm{K}_{\mathrm{f}}$ and $\mathrm{n}$ are Freundlich constants showing the adsorption capacity $(\mathrm{mg} / \mathrm{g})$ and intensity, respectively. They were obtained from the plot of $\log q_{\mathrm{e}}$ versus $\log \mathrm{C}_{\mathrm{e}}$.

\section{RESULTS AND DISCUSSION}

\section{SEM image analysis of CTAB-MMT}

The morphologies of purified MMT and CTAB-MMT are shown in Fig. 1. It can be seen from the Fig. 1 that purified MMT shows a small particles and nonporous surface, but the introduction of CTAB has led to a large particles and coarse porous surface. The incorporation of $\mathrm{CTAB}$ can form large particles and numerous cavities, which may be convenient for the penetration of dye molecules into the cavities of CTAB-MMT and results in an increase of the adsorption capacity of RR 198 on CTAB-MMT.

\section{XRD and FT-IR analyses of CTAB-MMT}

Fig. 2 illustrates the XRD patterns of purified MMT and CTAB-MMT. Increase of layers distances after modification of MMT using surfactant can be contributed to the surfactant inserting between the layers.
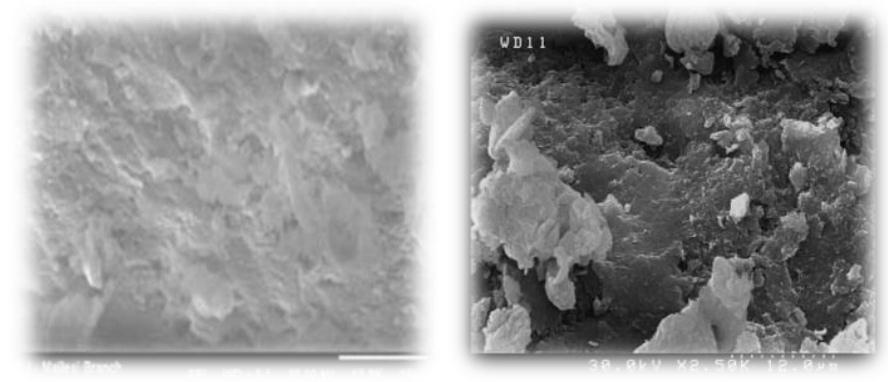

Figure 1. SEM images of purified MMT (left) and CTAB-MMT (right).
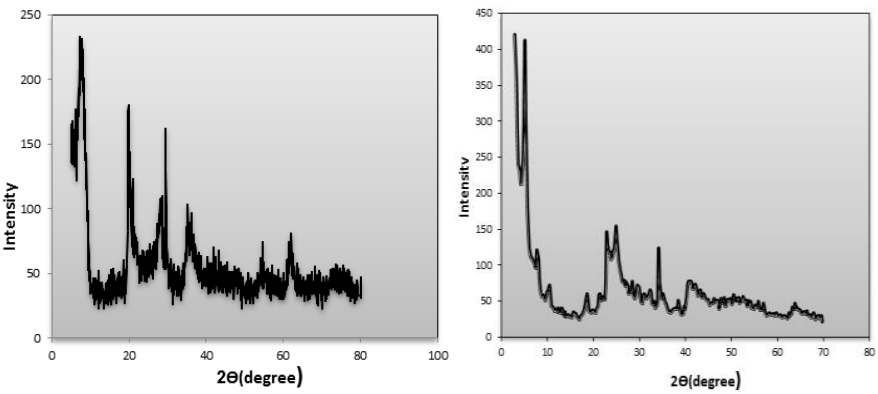

Figure 2. XRD patterns of purified MMT (left) and CTAB-MMT (right).

The FT-IR spectra of MMT and CTAB-MMT were taken in the range of 400$4000 \mathrm{~cm}^{-1}$ and compared to each other (Fig. 3). The absorption peaks at 3400$3650 \mathrm{~cm}^{-1}$ indicate the $\mathrm{H}-\mathrm{O}-\mathrm{H}$ stretching vibration bands of water molecules 
weakly hydrogen bonded to the $\mathrm{Si}-\mathrm{O}$ surface, and to the $-\mathrm{OH}$ stretching vibration of adsorbed water. Peak areas and intensities decrease after modification due to the bound water content decreases after modification [22]. The bands at 2927 and $2854 \mathrm{~cm}^{-1}$ were attributed to the alkyl C-H stretching mode. These results indicate that $\mathrm{CTAB}$ molecules were inserted into the interlayer space of the MMT [23]. The small band at $1635 \mathrm{~cm}^{-1}$ corresponded to the $\mathrm{SiO}-\mathrm{H}$ deformation vibration. The intensive band at around $1040 \mathrm{~cm}^{-1}$ can be assigned to $\mathrm{Si}-\mathrm{O}$ bending vibration. The $\mathrm{Al}-\mathrm{O}-\mathrm{Si}$ and $\mathrm{Si}-\mathrm{O}-\mathrm{Si}$ bending vibrations appeared at 525 and $465 \mathrm{~cm}^{-1}$, respectively [24].
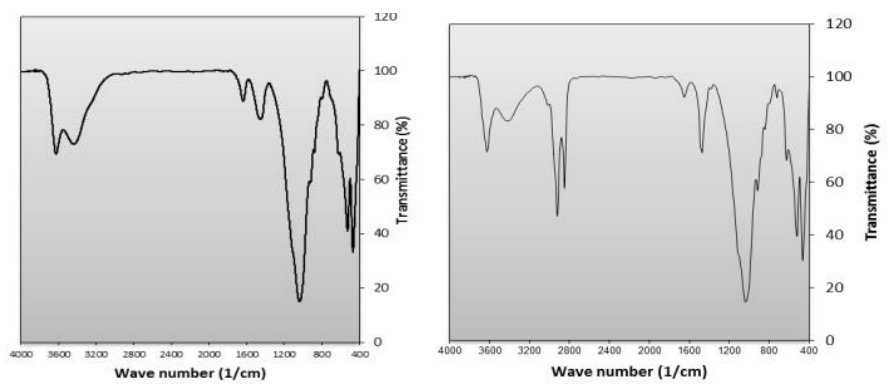

Figure 3. FT-IR spectra of purified MMT (left) and CTAB-MMT (right).

\section{Determine the optimum cation exchange capacity for CTAB-MMT}

MMT was modified with CTAB applied in different doses varying from 20 to $200 \%$. Fig. 4 presents the effect of cation exchange capacity (\% CEC) on the removal efficiency of RR 198. It is observed increasing CEC percentage leads to increase of removal efficiency from 63 to $93 \%$ and then decreased. As shown in Fig. 4, the maximum amount of dye removal was obtain in $70 \%$ CEC. Therefore, $70 \% \mathrm{CEC}$ was selected as the optimum CEC for subsequent experiments.

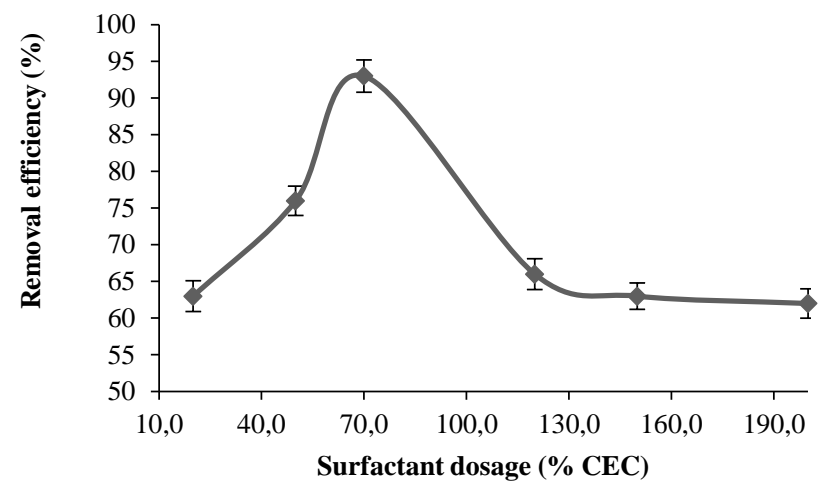

Figure 4. The effect of CEC on removal efficiency of RR 198 by CTABMMT. Experiment conditions: pH; 7, dye solution volume; $100 \mathrm{~mL}$, dye concentration; $100 \mathrm{mg} / \mathrm{L}$, adsorbent dosage; $1 \mathrm{~g}$, and contact time; $60 \mathrm{~min}$, temperature; $20^{\circ} \mathrm{C}$.

\section{Effect of pH}

In the present study, the effect of solution $\mathrm{pH}$ on the adsorption of RR 198 dye was investigated at different $\mathrm{pHs}$ from 2 to 11 . The adsorption of dye onto the adsorbent is significantly dependent on the solution $\mathrm{pH}$ which can influences the structure of dye and the adsorbent surface properties [25]. The results show that the maximum amount of adsorbed dye onto the CTAB-MMT was at $\mathrm{pH} 3$. At lower $\mathrm{pH}$ values, a decrease in adsorption efficiency is observed which can be attributed to the surface charge of the adsorbent. CTAB-MMT due to oxygen atoms has negatively charged adsorption sites, but it is positively charged at low $\mathrm{pH}$ values. Therefore, increase of the repulsion interactions between protonated amine groups of dye molecules and the positively charged adsorbent sites reduced the efficiency of adsorption [26]. However, at higher $\mathrm{pHs}(1<\mathrm{pH}<3)$, the positive surface charge of the CTAB-MMT is decreased and lead to increase adsorption efficiency up to $\mathrm{pH} 3$. On the other hand, $\mathrm{OH}^{-}$presence in the alkaline conditions leads to adsorption of the hydroxide ions on the surface's active sites in competence with the dye species, which reduces the efficiency of adsorption process [27]. However, electrostatic interactions are not only forces between dye molecules and adsorbent. It is important to remember that Van der Waals forces may be existed between dye molecules and alkyl chain of CTAB, which complicated the adsorption mechanism.

\section{Effect of contact time}

To determine the optimal reaction time, various contact times in the range of 10-150 min were investigated at the ambient temperature. The results show that the RR 198 adsorption increased initally, then slowely decreased untill reached to equilibrium at $60 \mathrm{~min}$. Afterwards, there was no considerbale diffrence in dye removal. Therefore, the optimum contact time was chosen as $60 \mathrm{~min}$. This phenomenon can be attributed to the availability of large number of vacant surface sites for dye adsorption at the initial stage, and after a lapse of time, the remaining vacant surface sites are difficult to be occupied due to repulsive forces between the solute molecules on the solid and bulk phases [3].

\section{Effect of adsorbent dosage}

The experiments were performed to determine the optimal CTAB-MMT dosage in different adsorbent dosage including $0.1,0.4,0.7$ and $1 \mathrm{~g}$. By increasing of the adsorbent dosage the RR 198 removal remains constant. Generally, the high adsorbent dosage causes to increase of total adsorption avilable sites. Hence, all dye molecules were adsorbed onto the surface per gram unit of CTAB-MMT and overall dye removal maintained constant [19]. Removal efficiency is constant over the range of $0.1-1 \mathrm{~g}$ adsorbent dosage. Conseqently, in order to reduce process cost $0.1 \mathrm{~g}$ was selected as the optimum adsorbent dosage.

\section{Effect of initial dye concentration}

Generally, the efficiency of adsorption process decreses with an increase in the initial dye concentration due to the saturation of active sites on the adsorbent. The dye concentration gradient between the aqueous and solid phases was act as driving force to dominate all mass transfer resistances [28]. The effects of initial dye concentration on the adsorption efficiency were studied at different dye concentration values including 20,60,100,140 and $180 \mathrm{mg} / \mathrm{L}$. The efficiency of dye removal is affected by the amount of the initial dye concentration, as can be observed with an increase in the initial dye concentration, the efficiency of dye removal was decreased. At lower dye concentrations, the number of available adsorption sites are relatively high and the dye molecules were easily adsorbed, vice versa at higher initial dye concentrations these sites were limited and dye removal efficiency was reduced [29]. Therefore, $20 \mathrm{mg} / \mathrm{L}$ was selected as the optimum initial dye concentration for subsequent experiments.

\section{Effect of ionic strength}

In order to investigate of ionic strength effect on the efficiency of dye removal, the dye solutions including various $\mathrm{NaCl}$ concentrations from 0 to $100 \mathrm{mg} / \mathrm{L}$ were prepared. It is observed, the efficiency of RR 198 adsorption on the adsorbent was decreased slightly with increasing ionic strength. The decrease in the amount of dye adsorption with increasing electrolyte concentration can be interpreted as reduction of the electrostatic interactions between dye molecules and adsorbent active sites due to increase of electrolyte ions concentration [27]. Consequently, for further experiments no electrolyte was added to the samples.

\section{Effect of temperature}

The influence of temperature on the efficiency of adsorption was studied at various temperature in the range of $15-45^{\circ} \mathrm{C}$. The obtained results show that the RR 198 removal slightly decreases with increasing temperature from 15 to $45^{\circ} \mathrm{C}$. This phenomenon indicates that the process of the removal of RR 198 by CTABMMT is exothermic in nature and seems to have a favourable adsorption at a lower temperature [21]. The reason for this behavior may be due to decrease the adsorptive forces between the adsorbate and adsorbent with an increase in temperature. Therefore, temperature of $15{ }^{\circ} \mathrm{C}$ was chosen as the optimum temperature in subsequent investigations.

\section{Adsorption kinetics}

Kinetic models reflect the relationship between an adsorption rate and equilibrium time. By adsorption kinetic models, the mechanism for RR 198 uptake rate and the residence time for the adsorption process can be defined. 
Under the optimum conditions, the RR 198 adsorption kinetic on CTAB-MMT was analyzed by using pseudo-first-order, pseudo-second-order, and intraparticle diffusion models [2].

The results show the adsorption kinetics of RR 198 on CTAB-MMT and the results of fitting adsorption data with the linearized plots pseudo-first-order and pseudo-second-order kinetics models are given in Table 1. The correlation coefficients $\left(\mathrm{R}^{2}\right)$ of pseudo-second-order model confirming better applicability of pseudo-second-order model compared to pseudo-first-order model.

As a result, the adsorption of RR 198 on CTAB-MMT is a chemisorption process. The adsorption process can be happen on the surface site of the adsorbent where there are an exchange or sharing of electrons via valance forces. The surface exchange reaction between the adsorbent and adsorbate lasts until the functional sites of the surface are fully seized. The assumptions used to verify pseudo-second-order is that the chemisorption acts as the rate limiting step. The adsorption process occures due to the valence forces between the dye and adsorbent [2].

The kinetics data for adsorption of RR 198 on CTAB-MMT was also analyzed with the intra-particle diffusion model. Since the pseudo-first-order and secondorder kinetic models are unable to evaluation of the diffusion mechanism Weber and Morris developed a widely accepted kinetic-based model that represents the time dependent intraparticle diffusion of components and showed that the sorption process is diffusion controlled if the rate is dependent upon the rate at which adsorbate and adsorbent diffuse towards each other [21].

Table 1. Kinetic parameters of three models for adsorption of RR 198 on the CTAB-MMT

\begin{tabular}{|c|c|c|c|c|c|c|c|c|}
\hline \multicolumn{3}{|c|}{ Pseudo-first-order model } & \multicolumn{3}{|c|}{ Pseudo-second-order model } & \multicolumn{4}{|c|}{ Intra-particle diffusion model } \\
\hline $\begin{array}{c}\mathrm{k}_{1} \\
(1 / \mathrm{min})\end{array}$ & $\begin{array}{c}\mathrm{q}_{\mathrm{e}} \\
(\mathrm{mg} / \mathrm{g})\end{array}$ & $\mathrm{R}^{2}$ & $\begin{array}{c}\mathrm{k}_{2} \\
(\mathrm{~g} / \mathrm{mgmin})\end{array}$ & $\begin{array}{c}\mathrm{q}_{\mathrm{e}} \\
(\mathrm{mg} / \mathrm{g})\end{array}$ & $\mathrm{R}^{2}$ & $\begin{array}{c}\mathrm{k}_{\mathrm{id}} \\
\left(\mathrm{mg} / \mathrm{gmin}^{1 / 2}\right)\end{array}$ & $\begin{array}{c}\mathrm{C} \\
(\mathrm{mg} / \mathrm{g})\end{array}$ & $\mathrm{R}^{2}$ \\
\hline 0.0198 & 4.14 & 0.7952 & 0.1315 & 92.59 & 0.9966 & 2.44 & 59.99 & 0.969 \\
\hline
\end{tabular}

\section{Adsorption isotherms}

Analysis of isotherm models is important for evaluating adsorption properties of CTAB-MMT. The Langmuir isotherm assumes that the adsorption happen in monolayer on a solid surface with a limit number of sites with identical energy and a maximum adsorption corresponds to a saturated monolayer of solute molecules on the adsorbent surface, while the Freundlich isotherm is based on the adsorption phenomenon take place in multilayer and on heterogeneous surface [30].

Under the optimum conditions, experimental data showed that the adsorption of RR 198 on the CTAB-MMT were fitted with Langmuir model $\left(\mathrm{R}^{2}=0.9958\right)$ under the tested concentrations. It can be concluded that the adsorption of RR 198 on the CTAB-MMT is limited to the monolayer formation on a homogeneous surface. the theoretical parameters of adsorption isotherms are presented in Table 2 .

Table 2. Isotherm parameters for adsorption of RR 198 on the CTAB-MMT.

\begin{tabular}{|c|c|c|c|c|c|}
\hline \multicolumn{3}{|c|}{ Langmuir isotherm } & \multicolumn{3}{c|}{ Freundlich isotherm } \\
\hline $\mathrm{q}_{\max }(\mathrm{mg} / \mathrm{g})$ & $\mathrm{K}_{\mathrm{l}}(\mathrm{L} / \mathrm{mg})$ & $\mathrm{R}^{2}$ & $\mathrm{n}$ & $\mathrm{K}_{\mathrm{f}}(\mathrm{mg} / \mathrm{g})$ & $\mathrm{R}^{2}$ \\
\hline 25.84 & 0.33 & 0.9958 & -0.081 & $5.38 \times 10^{18}$ & 0.6848 \\
\hline
\end{tabular}

\section{CONCLUSION}

In this study, for the first time adsorption of RR 198 on the CTAB-MMT was investigated and optimized. Based on the results, the maximum uptake of RR 198 was obtained at $\mathrm{pH} 3$ that resulted from the electrostatic interactions between the positively charged CTAB-MMT surface and the anionic dye species. However, electrostatic interactions are not only forces between dye molecules and adsorbent. It is important to remember that Van der Waals forces may be existed between dye molecules and alkyl chain of CTAB, which complicated the adsorption mechanism. Under the optimum conditions, the maximum removal efficiency and adsorption capacity of RR 198 on the CTAB-MMT were $99.61 \%$ and $25.84 \mathrm{mg} / \mathrm{g}$, respectively.
The adsorption isotherm and kinetic data were fitted with the Langmuir and pseudo-second-order kinetic models, respectively. The modified clay successfully was applied to remove the RR 198 from aqueous phase.

\section{CONFLICT OF INTEREST}

The authors declare no conflict of interest, financial or otherwise.

\section{ACKNOWLEDGEMENTS}

This work was financially supported by West Tehran Branch, Islamic Azad University, Tehran, Iran.

\section{REFERENCES}

1. P. Zhang, Q. An, J. Guo, C.C. Wang, J. Colloid Interface Sci. 389, 10, (2013)

2. W. Cheah, S. Hosseini, M.A. Khan, T. Chuah, T.S. Choong, Chem. Eng. J. 215, 747, (2013)

3. E. Bazrafshan, A.A. Zarei, H. Nadi, M.A. Zazouli, Indian J. Chem. Technol. 21, 105, (2014)

4. M. Dehghani, M.M. Taghizadeh, T. Gholami, M. Ghadami, L. Keshtgar, Z. Elhameyan, M.R. Javaheri, N. Shamsedini, F. Jamshidi, S. Shahsavani, M. Ghanbarian, Jundishapur J. Health Sci. 7, 38, (2015)

5. M. Alizadeh, E. Bazrafshan, A.H. Mahvi, F. Kord Mostafapour, E. Ghahremani, Sci. J. Kurdistan Univ. Med. Sci. 19, 124, (2014)

6. M.A. Zazouli, D. Balarak, Y. Mahdavi, M. Ebrahimi, Iran J. Health Sci. 1, 36, (2013)

7. M. Hadi, M.R. Samarghandi, G. McKay, Chem. Eng. J. 160, 408, (2010)

8. A. Esmaeili, M. Kalantari, Desalination Water Treat. 57, 6401, (2016)

9. K. Nadafi, M. Vosoughi, A. Asadi, M. Omidvar Borna, M. Shirmardi, J. Water Chem. Technol. 36, 125 (2014)

10. D. Ghemati, D. Aliouche, J. Water Chem. Technol. 36, 265, (2014)

11. H. Biglari, S. Rodríguezí Couto, Y.O. Khaniabadi, H. Nourmoradi, M Khoshgoftar, A. Amrane, M. Vosoughi, S. Esmaeili, R. Heydari, M.J. Mohammadi, R. Rashidi, Int. J. Chem. React. Eng. 16, 20170064, (2018)

12. Y.O. Khaniabadi, R. Heydari, H. Nourmoradi, H. Basiri, H. Basiri, J. Taiwan Inst. Chem. Eng. 68, 90, (2016)

13. H. Godini, A. Sheikhmohammadi, L. Abbaspour, R. Heydari, G.S Khorramabadi, M. Sardar, Z. Mahmoudi, Optik 182, 1194 (2019)

14. T. Ahmadifard, R. Heydari, M.J. Tarrahi, G.S. Khorramabadi, Int. J. Chem React. Eng. 17, 20180154, (2019)

15. B. Kamarehie, F. Ahmadi, F. Hafezi, A. Abbariki, R. Heydari, M.A. Karami Data Brief 18, 96, (2018)

16. S.S. Stavitskaya, V.M. Vikarchuk, M.F. Kovtun, O.I. Poddubnaya, A.M. Puziy, J. Water Chem. Technol. 36, 110, (2014)

17. N.A. Klymenko, G.M. Zdorovenko, I.A. Shevchuk, L.R. Reshetniak, I.Y Roi, L.K. Patiuk, J. Water Chem. Technol. 35, 43, (2013)

18. M.T. Uddin, M. Rukanuzzaman, M.M.R. Khan, M.A. Islam, J. Environ Manage. 90, 3443, (2009)

19. L. Wang, A. Wang, J. Hazard. Mater. 160, 173, (2008)

20. M. Huskić, M. Žigon, M. Ivanković, Appl. Clay Sci. 85, 109, (2013)

21. Toor, M. and Jin, B., Chem. Eng. J. 187, 79, (2012)

22. J. Ma, J. Qi, C. Yao, B. Cui, T. Zhang, D. Li, Chem. Eng. J. 200, 97, (2012)

23. X. Xin, W. Si, Z. Yao, R. Feng, B. Du, L. Yan, Q. Wei, J. Colloid Interface Sci. 359, 499, (2011)

24. L. Zhirong, M.A. Uddin, S. Zhanxue, Spectrochim. Acta, Part A 79, 1013 (2011)

25. M.F. Hou, C.X. Ma, W.D. Zhang, X.Y. Tang, Y.N. Fan, H.F. Wan, J. Hazard. Mater. 186, 1118, (2011)

26. Ö. Gök, A.S. Özcan, A. Özcan, Appl. Surf. Sci. 256, 5439, (2010)

27. A. Tabak, N. Baltas, B. Afsin, M. Emirik, B. Caglar, E. Eren, J. Chem. Technol. Biotechnol. 85, 1199, (2010)

28. Z. Aksu, A.B. Akın, Chem. Eng. J. 165, 184 (2010)

29. G.Q. Wu, X. Zhang, H. Hui, J. Yan, Q.S. Zhang, J.L. Wan, Y. Dai, Chem Eng. J. 185, 201, (2012)

30. A.A. Jalil, S. Triwahyono, S.H. Adam, N.D. Rahim, M.A.A. Aziz, N.H.H Hairom, N,A,M, Razali, M.A.Z. Abidin, M.K.A. Mohamadiah, J. Hazard. Mater. 181, 755, (2010) 